\title{
Approaches to dating deformation using the K-Ar decay system
}

\section{DAWN A KELLETT}

\author{
Natural Resources Canada
}

Presenting Author: dawn.kellett@canada.ca

Approaches to dating deformation using the K-Ar decay system

\section{Kellett, Dawn A.}

${ }^{1}$ Geological Survey of Canada, 1 Challenger Dr., Dartmouth, Nova Scotia, Canada, B2Y 4A2; dawn.kellett@canada.ca

The absolute timing of deformation is a critical piece of information for reconstructing the assembly and re-organization of the Earth's crust, relating deformation to driving forces, developing plate tectonic reconstructions, tracking structural pathways of ore-bearing fluids, and investigating fault-related geohazards. The K-Ar decay system is widely used to determine cooling ages for igneous and metamorphic rocks and minerals, because $\mathrm{Ar}$ undergoes thermal diffusion under mineral-specific thermal conditions. However, the K-Ar decay system also has great potential for direct dating of certain types of deformation products, at temperatures under which thermal diffusion of $\mathrm{Ar}$ is inefficient. These low-temperature situations can include cleavage-forming mica, fault-generated illite-rich gouge in brittle fault systems and dynamically-recrystallized mica in lowtemperature mylonites. Radiogenic ${ }^{40} \mathrm{Ar}$ reservoirs in minerals forming during or subject to deformation may be disturbed or reset by a variety of processes besides pure thermal diffusion, including intra-grain deformation, recrystallization and interaction with fluids. Consequently, interpreting dates obtained using the K-Ar decay system as deformation ages requires the integration of detailed information about the source rocks/protoliths, conditions of deformation, potential sources and sinks of ${ }^{40} \mathrm{Ar}$, chemistry of the dated minerals, as well as complimentary geochronological/thermochronological information. Where possible, spatially-resolved in situ analysis of ${ }^{40} \mathrm{Ar}$ can also aid interpretations. In this presentation, a range of case studies will be used to explore various approaches to dating deformation using the K-Ar decay system, and how analytical strategy can reduce some interpretational ambiguities. 